\title{
Design, Fabrication and Analysis of Varying Loads on Speed Hump
}

\author{
Sasidhar.G ${ }^{1}$, Leela Prasad. ${ }^{2}$, Mahesh Kumar. $G^{3}$, Chaitanya Vardhan.B ${ }^{4}$, Prudhvi Kumar. $G^{5}$ \\ Mechanical Engineering 1,2,3,4,5, Assistant professor, GMRIT, Rajam ${ }^{1}$, Graduates, GMRIT, Rajam ${ }^{2,3,4,5}$ \\ Email: sasidhargurugubelli@gmail.com ${ }^{1}$, Sasidhar.g@gmrit.org ${ }^{2}$
}

\begin{abstract}
In the present scenario technology increases day by day and power usages also increasing gradually. Day to day increase in population, power requirement is more and conventional sources are lessening. We must depend on the non-conventional sources for power generation. As a mechanical branch student, we always looking for the opportunities to utilize the conceptual knowledge of the subject. From the back-ground study of different papers large amount of energy is wasted at the speed breakers in the form of a kinetic, potential and frictional energy, when the vehicles pass over a speed breaker. This project attempts to show how energy can tapped and used for commonly used system, generation of electricity through the speed breaker mechanism. This system involves rack and pinion gear, springs and a base plate. The rack and pinion will helpful to convert the kinetic energy produced by the vehicles to mechanical energy. Then the mechanical energy is converted to electrical energy by using the cycle crank and free wheel mechanism. This mechanism consists of two shafts, cycle free wheel, crank wheel and chain. One shaft connected with rack and pinion at one end and the other end connected with cycle crank wheel. This shaft is connected with another shaft by using chain mechanism which carry free wheel at one end at the other end connected with motor.
\end{abstract}

Index Terms: Speed Hump, Rack-Pinion, Power, Energy, Mechanism.

\section{INTRODUCTION:}

There are 10 main different sources of energy that are used in the world to generate power. While there are other sources being discovered all the time, none of them has reached the stage where they can be used to provide the power to help modern life go. All of these different sources of energy are used primarily to produce electricity. The world runs on a series of electrical reactions - whether you are talking about the car you are driving or the light you are turning on. All of these different sources of energy add to the store of electrical power that is then sent out to different locations via high powered lines.

\subsection{Conventional energy sources}

These sources of energy are also called nonrenewable sources. These sources of energy are in limited quantity except hydro-electric power. These are coal, petroleum and electricity. These are called commercial energy because they have a price and consumer has to pay the price to purchase them. Coal is the major source of energy. Coal deposits in India are 148790 million tonnes. Total lignite reserves found at Neyveli are 3300 million tonnes. In 1950-51, annual production of coal was 32 million tonnes. In 2005-06, annual production of coal was 343 million tonnes. Lignite production was 20.44 million tonnes in 2005-06. According to an estimate, coal reserves in India would last about 130 years. India is now the fourth largest coal producing country in the world. Coal deposits are mainly found in Orissa, Bihar, Bengal and Madhya Pradesh. It provides employment to 7 lakh workers. In 1950-51, the total production of oil in India was 0.3 million tonnes. It increased to 32.4 million tonnes in 2000 01. Despite tremendous increase in oil production.
India still imports $70 \%$ of has oil requirements from abroad. In 1951, there was only one oil refinery in Assam.

After independence 13 such refineries were set up in public sector and their refining capacity was 604 lakh tonnes. After implementation of economic reforms, private refineries are also engaged in oil refining. As per current rate of consumption, oil reserves in India may last about 20 to 25 years. Agricultural wastes like straw are used as fuel for cooking purposes. According to one estimate agricultural waste used for fuel might be 65 million tonnes. Animal dung when dried is also used for cooking purposes. Total animal dung production is 324 million tonnes out of which 73 million tonnes are used as fuel for cooking purposes. The straw and dung can be used as valuable organic manure for increasing fertility of soil and in turn productivity.

\subsection{Non-conventional energy sources}

Besides conventional sources of energy there are non-conventional sources of energy. Examples are Bio energy, solar energy, wind energy and tidal energy. Govt. of India has established a separate department under the Ministry of Energy called as the Department of Non-conventional Energy Sources for effective exploitation of nonconventional energy. These are the main sources to produce electricity as shown in figure 1 .

1) Solar Energy

2) Wind Energy

3) Geothermal Energy

4) Hydrogen Energy

5) Tidal Energy

6) Wave Energy

7) Hydroelectric Energy

8) Biomass Energy 
9) Nuclear power

10) Fossil fuels

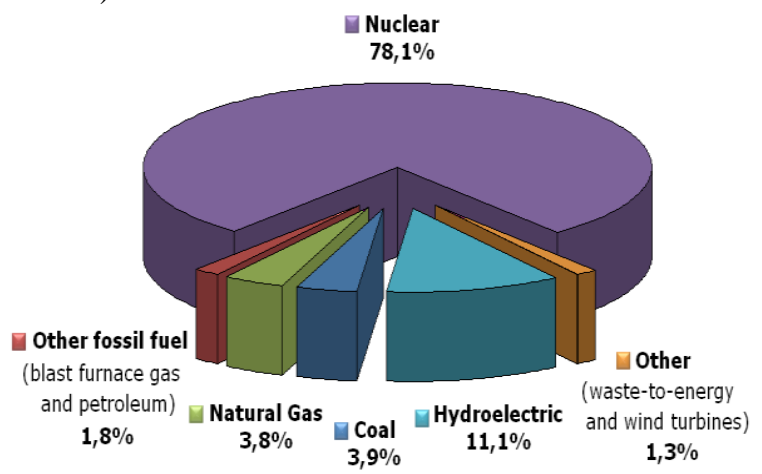

Fig. 1. Electricity production from various sources.

\section{2 . LITERATURE REVIEW}

The number of vehicles passing over the speed breaker in roads is increasing day by day. A large amount of energy is wasted at the speed breakers through the dissipation of heat and also through friction, every time a vehicle passes over it. There is great possibility of tapping this energy and generating power by making the speed-breaker as a power generation unit. The generated power can be used for the lamps, near the speed breakers.[1] Market failure is possible when monopoly manipulation of markets occurs. A crisis can develop due to industrial actions like union organized strikes and government embargoes. The cause may be ageing over-consumption, infrastructure and sometimes bottlenecks at oil refineries and port facilities restrict fuel supply. An emergency may emerge during unusually cold winters. Emerging shortages Crisis that currently exist include. The availability of regular conventional fossil fuels will be the main sources for power generation, but there is a fear that they will get exhausted eventually by the next few decades. [2] In a developing country like Bangladesh, energy source crisis to generate electricity is a major issue which almost hampers all developments. In Bangladesh only about $32 \%$ of the total population has access to use electricity and $6 \%$ to natural gas. But in rural area only $22 \%$ has electricity without gas supply. Because of the high consumption rate of fossil fuel, it will be over near future. Crude oil consumption has increased radically from recent observation which mostly used to generate electricity. Bangladesh imports 3.5-4.0 million tons of petroleum and petroleum products per year that spent about $\$ 5$ million in 2011 which is $10 \%$ more expense compare to year 2000.[3-4]

\section{METHODOLOGY}

\subsection{Construction of the model}

At this point we are taking two base plates on which the four hollow pillars are mounted which gives support to the equipment. The entire setup is divided into two sections. The first section comprises of springs and rack and pinion. Similarly, on the other section freewheel and motor is placed. Here the pillars are in such a way that the inner diameter of the pillars on top base plate is larger than the bottom plate. Two hollow cylinders are mounted in between two pillars on top base plate and similarly on bottom base plate. In between these two springs we are going to place a rack and pinion which is placed on the top base plate. Further the pinion is connected to a shaft on which crank wheel is mounted on one end. From here the power is transmitted to the other side by means of a chain. Here the chain is connected to the cycle's freewheel which is mounted on another shaft. The freewheel is placed on same side parallel to the crank wheel. The purpose of using freewheel is to give continuous motion in one direction. On the same shaft on the other end D.C motor is placed from which the power is supplied.

\subsection{Working process}

While moving, the vehicles have some active vitality and it is being squandered. This dynamic vitality can be used to create control by utilizing a unique course of action called Power Hump. It is an ElectroMechanical unit. It uses both mechanical advancements and electrical systems for the power age and its stockpiling. Power Hump is a vault like gadget liable to be speed breaker. At whatever point the vehicle is permitted to ignore the vault it gets squeezed downwards then the springs are appended to the arch are packed and the rack which is connected to the base of the vault moves descending in responding movement.

Since the rack and pinion is in contact with the shaft. When the vehicle moves over the hump the pressure is applied on the base plate and it starts compressing because of the springs. As the pinion starts rotating along with it the shaft also rotates because pinion is in contact with the shaft. Crank wheel comes into picture which transmits motion to the other side by means of a chain. The chain is connected the freewheel which is mounted on the other shaft here the main use of freewheel is that it only makes the shaft to rotate in uni-directional motion. There the motion from the freewheel is transmitted to the motor which produces power.

\subsection{Rack and pinion mechanism}

Speed breaker power generator Converters fundamentally new idea of non-ordinary vitality age. It is electro-mechanical vitality creating machine. This machine changes over responding movement in to rotational movement. The rotational power is put away in crank and freewheel pivots dynamo, which creates power. Here first critical point is the way we get responding movement, which is prime contribution to the framework. For that we use weight of Moving vehicle on the Speed breaker. We put our machine underneath the Speed breaker introducing distinctive units. Every one of the units are associated with the regular shaft utilizing chain and sprocket drive. The head of rack is raised to 
level underneath the speed breaker surface. At the point when vehicle proceeds onward the speed breaker, the rack it will be pushed down. As shown in the figure 2 the rack is connected with free wheel type pinion that turns in a single course as it were. The rack and pinion plan convert responding movement in to rotational movement. A "generator" and "engine" is basically a similar thing: A generator produces power. In a generator, something makes the pole and armature turn. This produced power energy is utilized for different application required by various client [5-6].

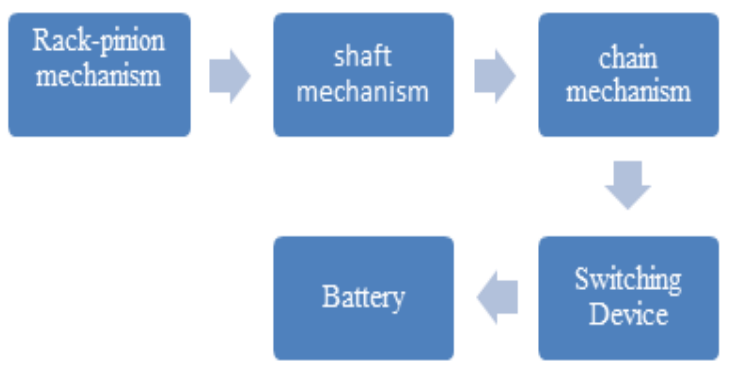

Fig. 2. Flow chart of the project working.

\subsection{Construction details}

The Various machine elements used in the construction of Power hump are

\section{$>$ RACK \& PINION \\ $>$ SPUR GEAR \\ $>$ FLY WHEEL \\ $>$ BEARINGS \\ $>$ SHAFT \\ $>$ SPRINGS \\ $>$ ELECTRIC DYNAMO}

\subsubsection{Rack \& Pinion}

A rack and pinion are a sort of direct actuator that involves a couple of apparatuses which convert rotational movement into straight movement. A round rigging called "the pinion" draws in teeth on a direct "gear" bar called "the rack" rotational movement connected to the pinion makes the rack move with respect to the pinion, in this way interpreting the rotational movement of the pinion into straight movement.

3.4.2 Fly Wheel

A flywheel is a mechanical gadget explicitly intended to proficiently store rotational vitality. Flywheels oppose changes in rotational speed by their snapshot of dormancy. The measure of vitality put away in a flywheel is corresponding to the square of its rotational speed. The best approach to change a flywheel's put away vitality is by expanding or diminishing its rotational speed by applying a torque lined up with its hub of symmetry. 3.4.3 Bearings

A direction is a machine component that compels relative movement to just the ideal movement, and decreases grinding between moving parts. The plan of the bearing may, for instance, accommodate free direct development of the moving part or with the expectation of complimentary revolution around a fixed hub; or, it might keep a movement by controlling the vectors of typical powers that bear on the moving parts. Most course encourage the ideal movement by limiting grating. Orientation are characterized comprehensively as indicated by the sort of activity, the movements permitted, or to the bearings of the heaps (powers) connected to the parts.

3.4.4 Shaft

A shaft is a turning machine component, normally round in cross area, which is utilized to transmit control starting with one section then onto the next, or from a machine which produces capacity to a machine which ingests power. The different individuals, for example, pulleys and gears are mounted on it.

3.4.5 springs

A spring is a flexible item that stores mechanical vitality. Springs are ordinarily made of spring steel. There are many spring structures. In ordinary use, the term regularly alludes to curl springs. When a conventional spring, without stiffness variability features, is compressed or stretched from its resting position, it exerts an opposing force approximately proportional to its change in length (this approximation breaks down for larger deflections). The rate or spring constant of a spring is the change in the force it exerts, divided by the change in deflection of the spring.

\subsection{Working procedure}

While moving, the vehicles have some active vitality and it is being squandered. This dynamic vitality can be used to create control by utilizing a unique course of action called POWER HUMP. It is an ElectroMechanical unit. It uses both mechanical advancements and electrical systems for the power age and its stockpiling. POWER HUMP is a vault like gadget liable to be speed breaker. At whatever point the vehicle is permitted to ignore the vault it gets squeezed downwards then the springs are appended to the arch are packed and the rack which is connected to the base of the vault moves descending in responding movement.

Since the rack and pinion is in contact with the shaft. When the vehicle moves over the hump the pressure is applied on the base plate and it starts compressing because of the springs. As the pinion starts rotating along with it the shaft also rotates because pinion is in contact with the shaft. Crank wheel comes into picture which transmits motion to the other side by means of a chain. The chain is connected the freewheel which is mounted on the other shaft here the main use of freewheel is that it only makes the shaft to rotate in uni-directional motion. There the motion from the freewheel is transmitted to the motor which produces power. 


\section{Available online at www.ijrat.org}

\section{DESIGN DETAILS:}

\subsection{Equipment specifications}

The following are the specification details of the project components.

\subsubsection{Rack and pinion}

- $\quad$ Rack length $=46 \mathrm{~cm}$

- $\quad$ Number of teeth on rack $=80$

- Diameter of pinion $=4 \mathrm{~cm}$

- $\quad$ Number of teeth on pinon $=22$

- Material of rack = cast iron

- Material of pinion = cast iron

- Properties of Material: carbon content more than $2 \%$, low melting point.

4.1.2 Base plates

- $\quad$ Length $=52 \mathrm{~cm}$

- $\quad$ Width $=32 \mathrm{~cm}$

- $\quad$ Thickness $=2 \mathrm{~mm}$

- Material of baseplate $=$ mild steel

- Properties of material: carbon content 0.05$0.25 \%$, low tensile strength.

4.1.3 Springs

- $\quad$ Length $=22 \mathrm{~cm}$

- Outer diameter, $\mathrm{D}_{\mathrm{o}}=8.6 \mathrm{~cm}$

- Inner diameter, $\mathrm{D}_{\mathrm{i}}=8 \mathrm{~cm}$

- Wire diameter $=0.6 \mathrm{~cm}$

- $\quad$ Spring constant $=$ nd

- Modulus of rigidity, $\mathrm{G}=78 \mathrm{Gpa}$ (Spring steel)

- Spring index $=\mathrm{C}=\mathrm{D} / \mathrm{d}$

Where, $\mathrm{D}=$ mean dia of the wire $=\frac{D_{0}+D_{i}}{2}=8.3 \mathrm{~cm}$, Spring rate $($ Stiffness $)=\mathrm{k}^{\prime}=\mathrm{w} / \bar{\delta}$;

$\mathrm{w}=$ load, $\delta=$ deflection

Pitch $(\mathrm{p})=$ free length $/ \mathrm{n}$ ' $1 ; \mathrm{n}^{\prime}=$ number of coils $=12$

$\mathrm{T}=\mathrm{w} \times \mathrm{D} / 2=\frac{\pi}{16} \times \tau 1 \times d^{\mathrm{a}}$

$\tau 1=\frac{\delta w D}{\pi d^{2}}$

$\tau 2=$ load/cross sectional area of wire

$=w / \frac{\pi}{4} \times d^{2}=4 w / \pi d^{2}$

Maximum shear stress reduced in spring $=\tau$

$8 \mathrm{kpc} / \pi d^{2}$

Deflection of spring (deformation) $\delta=8 \mathrm{wD}^{3} \mathrm{n} / \mathrm{Gd}^{4}$

$\delta=\frac{8 \times(100 \times 9.81) 83^{8} \times 12}{78 \times 10^{8} \times 6^{4}}=158 \mathrm{~mm}$ (for two

springs)

4.1.4 Crank wheel

- $\quad$ Diameter $=14 \mathrm{~cm}$

- $\quad$ Number of teeth $=48$

- Material = aluminum alloy or steel

- Composition of the material $=$ alloying elements are $\mathrm{Cu}, \mathrm{Mg}, \mathrm{Si}, \mathrm{Zn}$.

4.1.5 Free wheel

- $\quad$ Outer diameter $=4 \mathrm{~cm}$

- $\quad$ Number of teeth $=18$

- Material = aluminum alloy or steel

- Composition of the material: alloying elements are $\mathrm{Cu}, \mathrm{Mg}, \mathrm{Si}, \mathrm{Zn}$.

\subsection{CAD Design of the project}

Components of the project has been designed using Fusion 360 CAD software. The CAD design details are provided below.

4.2.1 Base plate

- Draw a rectangular sketch on base plate.

- Extrude the sketch up to the required thickness.

4.2.2 Spring

- Draw a circular spiral sketch on the any of the selected axis.

- Take a new plane along the spiral sketch.

- Select 'sweep' option to draw the circular sketch as profile and the path as spiral sketch.

- Then press OK button.

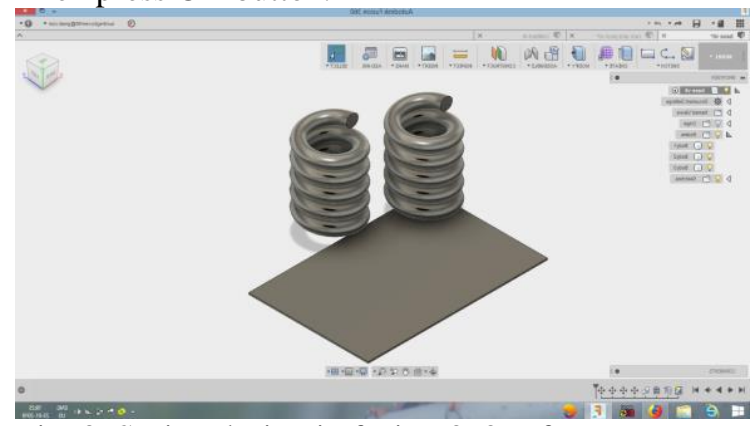

Fig. 3. Spring design in fusion 360 software 4.2.3 Rack

- Draw a rectangle on the side plane.

- Draw trapezoidal sketch on the rectangle one.

- Using rectangle pattern select trapezoidal part and select 10 option and then press OK button.

- Trim the unwanted parts.

- Extrude the sketch up to required width. 4.2.4 Pinion

- Draw two circles on the base plane.

- Draw the trapezoidal sketch on the circular sketch.

- Using circular pattern make it as 27.

- Trim the unwanted sketching. Extrude the main sketch up to the width of the gear.

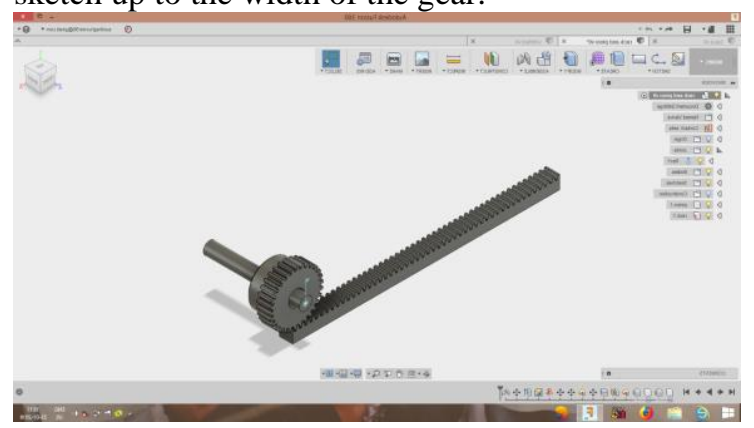

Fig. 4. Rack \& Pinion design in fusion 360 software

\subsubsection{Sprocket}

Same procedure as pinion design from (1) to (4) and draw 3 circles at last make fillet to the third circle as ped.

$$
\mathrm{P}=\frac{2 \pi \mathrm{NT}}{60}
$$

$\mathrm{N}=60 \mathrm{RPM}$ (by considering from the literature) $\mathrm{T}=\mathrm{F} \times \mathrm{r}=\max$ 


\section{Available online at $w w w . i j r a t . o r g$}

$$
\begin{aligned}
& =100 \times 9.81 \times 0.025 \\
& =24.52 \mathrm{~N}-\mathrm{m} \\
& \quad \mathrm{P}=\frac{2 \mathrm{mNT}}{60}=15.841 \mathrm{~W}
\end{aligned}
$$

Speed values at different load trials: shown in the figure 5 .

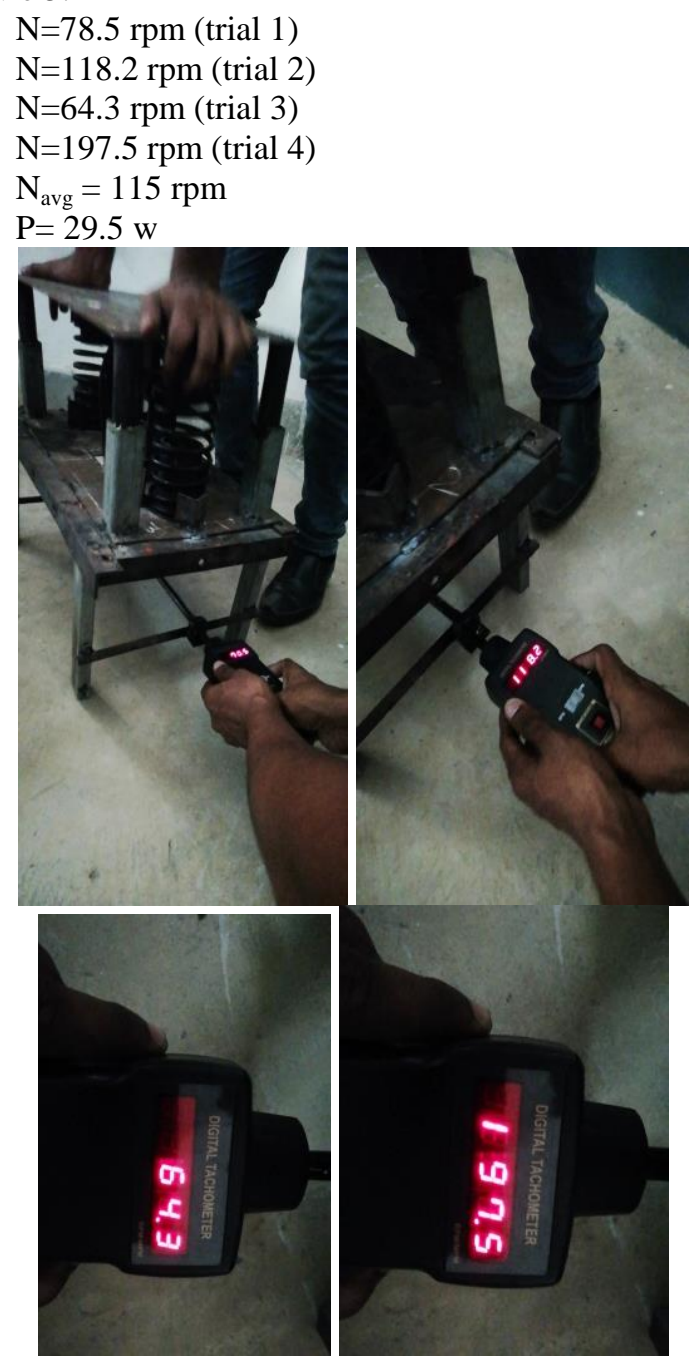

Fig. 5. Speed measuring with Tachometer

\section{RESULTS AND DISCUSSIONS}

From the testing above setup, different loads were acted like $50 \mathrm{~kg}, 75 \mathrm{~kg}, 100 \mathrm{~kg}, 125 \mathrm{kgs}$ respectively., by acting the loads we get different rpm for the shaft. We get $64 \mathrm{rpm}, 78 \mathrm{rpm}, 118 \mathrm{rpm}$ and $189 \mathrm{rpm}$. Based on the average rpm we can get 29.5-watt power. If we place this set up shown in figure 6 in a heavy traffic road then we get more power because load of a vehicle is much more compared with the man load. Like buses, trucks have high weight.

This is generating many kilowatts power by using downward as well as the upward motion of rack. With the help of speed breaker mechanism, linear motion of rack is converted into rotary motion of pinion and thus is used to rotate the shaft of DC generator. It generates 273.24 watts with $400 \mathrm{~kg}$ of load and $14 \mathrm{~cm}$ of the height of the rack. DC voltages charge the batteries during the passage of moving vehicles. Using inverter (DC to AC conversion), we will be able to use batteries power for other useful applications. It can be implemented on the toll plazas, highways. Guide slots and lubricating oil sump is required to minimize friction losses. The initial cost of this arrangement is high but after the first cost, it will be free energy system.

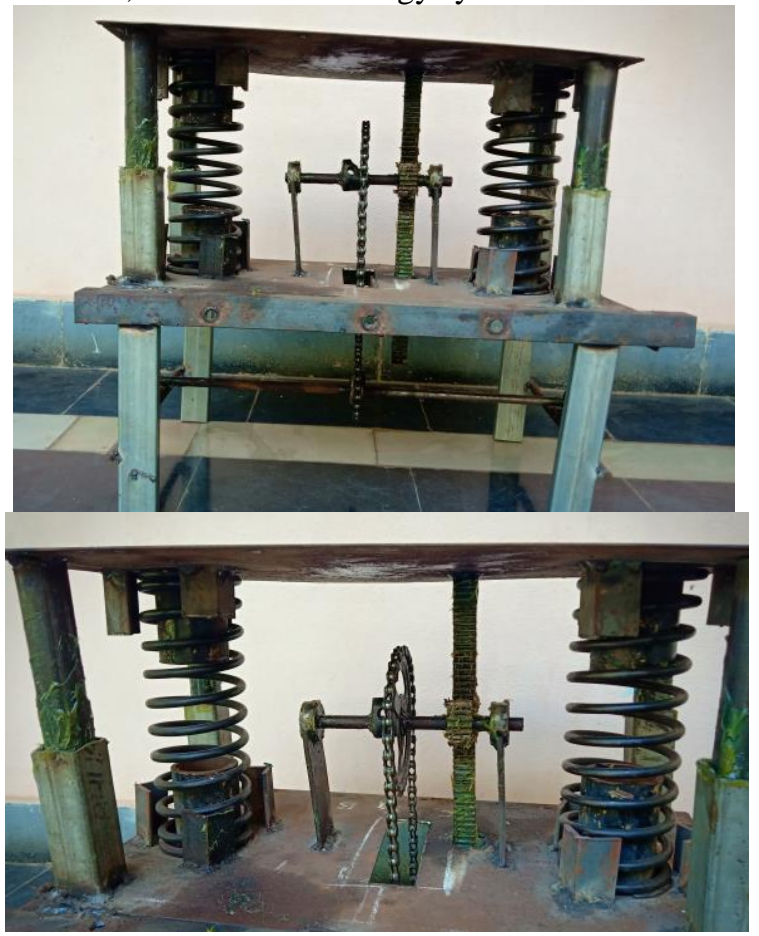

Fig. 6. Final assembly of the project

\section{CONCLUSIONS}

- In this study a new technique has been proposed to get electricity from speed breakers. This technique will help to conserve our natural resources.

- In the current model, the rollers are covered with plain rubber to increase the friction between the rollers. It can be replaced with another material with a coarse texture to provide better grip between the tires and the rollers.

- The chain drive can be replaced with a V-belt drive. This would reduce the shocks and vibration caused when under heavy load. Also Belt drives do not require lubrication which would decrease maintenance costs.

- The bearings can be replaced with more durable plumber bearings reducing the chance of failure.

- The material of the rollers can be made lighter so as to increase the efficiency. The mild steel used in this model can be replaced by aluminum alloy 6063 or 6061 .

- Suitable at parking of multiplexes, malls, toll booths, signals, etc.

- Such speed breakers can be designed for heavy vehicles, thus increasing input torque and ultimately output of generator. 


\section{REFERENCES}

[1] Piyush bhagdikar, jagadeeswaran $\mathrm{n}$ and Navneet rana, "Generation of electricity with the use of speed breaker". International journal advances in engineering and technologies. (IJAET) May 2014.

[2] G.Ramakrishna Prabu, "Electricity Generation by Speed Breaker".international journal of advanced in electrical, economicsand instrumentation engineering. Volume 4, issue 5, may 2015.

[3] Md Shahdat Hossan, ck das, "Electricity from Wasted Energy of the Moving Vehicle Using Speed Breaker". Journal teknologi, February 1, 2015.

[4] Mithul patel, "A study on Speed Breakers". International Journal of Advance Engineerin and Research Development (IJAERD) Volume 4, Issue 3, March -2017.

[5] Anket Mishra, "electricity generation from speed breakers." The International Journal of Engineering and Science (IJES) Volume 2, Issue 11, Pages 25-27,2013.

[6] Miss. Shraddha Deshpande, Miss Bhagya sri Kulkarni, "electricity generation using speed breaker." International research journal of engineering and technology. Volume 3, issue 2, 2016.

[7] Abdulrazzak Pathan, ankite garate, and Karthikeyan n, "power generation through speed breaker." Sreeram polytechnic. 